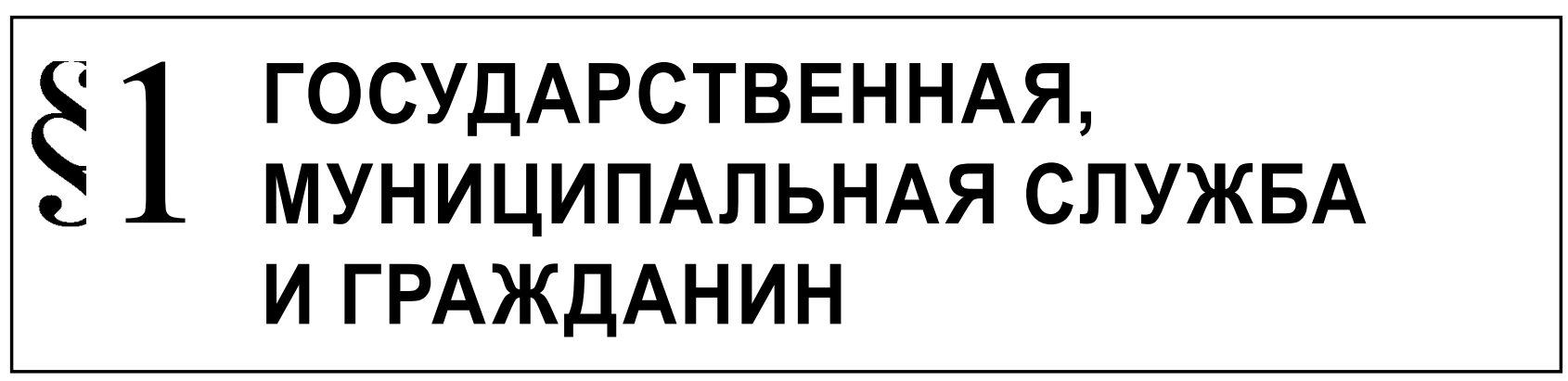

Черногоров Д.А.

\title{
ПУБЛИЧНАЯ СЛУЖБА И ДОЛЖНОСТНОЕ ЛИЦО
}

\begin{abstract}
Аннотация: Институт «должностного лица» в срере государственного управления привлекал к себе внимание ученых разных поколений. Теоретические основы исследования института "должностного лица» были заложены еще в научных трудах ученых-государствоведов конца ХІХ в. - начала XX в. Но особый интерес институт "должностного лица» приобрел с середины 90-х годов ХХ в. Это время можно охарактеризовать этапом интенсивного реформирования института государственной службы и административно-деликтного законодательства. В этот период предпринимаются попытки обосновать необходимость выработки единого межотраслевого понятия "должностное лицо», а также определяются возможные пути для уяснения его административно-правового содержания. Методологическую основу статьи составили современные достижения теории познания. В процессе исследования применялись общефилософский, теоретический, общефилософские методы (диалектика, системный метод, анализ, синтез, аналогия, дедукция, наблюдение, моделирование), традиционно правовые методы (формально-логический), а также методы, используемые в конкретно-социологических исследованиях (статистические, экспертные оценки и др.). На сегодняшний день отечественное законодательство о государственной службе находится на этапе становления. Несмотря на реализованные в последние годы меры, все еще не удается достигнуть качественной правовой регламентации отношений по прохождению государственной службы. Так и остаются неразрешенными проблемы, связанные с коррумпированностью государственной службы, недостаточным профессиональным уровнем подготовки государственных служащих, отсутствием современных методов планирования труда государственных служащих и т.п.
\end{abstract}

Ключевые слова: служба, должность, функция, полномочие, лицо, коррупция, публичность, управление, право, обязанность.

$\mathrm{H}$ а сегодняшний день отечественное законодательство о государственной службе находится на этапе становления. Несмотря на реализованные в последние годы меры, все еще не удается достигнуть качественной правовой регламентации отношений по прохождению государственной службы. Так и остаются неразрешенными проблемы, связанные с коррумпированностью государственной службы, недостаточным профессиональным уровнем подготовки государственных служащих, отсутствием современных методов планирования труда государственных служащих и т.п.

Указанные проблемы не остаются не замеченными на официальном уровне. Например, недавно завершилась реализация утвержденной Указом Президента от 10 марта 2009 г. № 261 Федеральной программы «Реформирование и развитие системы государственной службы Российской Федерации (2009-2013 годы)».

Ее основной целью являлось создание целостной системы государственной службы посредством завершения реформирования ее видов и создания системы управления государственной службой, формирования высококвалифицированного кадрового состава государственной службы, обеспечивающего эффективность государственного управления, развитие гражданского общества и инновационной экономики.

В связи с этим в Программе были выделены следующие основные направления реформирования и развития системы государственной службы Российской Федерации:

\footnotetext{
СЗ РФ. 2009. № 11. Ст. 1277.
} 
- формирование системы государственной службы Российской Федерации как целостного государственно-правового института, создание системы управления государственной службой;

- $\quad$ внедрение на государственной службе Российской Федерации эффективных технологий и современных методов кадровой работы;

- повышение эффективности государственной службы Российской Федерации и результативности профессиональной служебной деятельности государственных служащих.

Положительно оценивая введенные благодаря указанной Программе новации, хочется высказать несколько новых идей, которые можно было бы реализовать при осуществлении правового регулирования в рассматриваемой сфере.

Прежде всего следует рассмотреть возможность включения в российское законодательство понятие «публичная служба», которое принято в общемировой правовой практике.

Ю.Н. Старилов в связи с этим отмечал следующее: «Было бы целесообразным формирование в теории и установление в законодательстве более общего и единого понятия, объединяющего все виды служащих, - служащие публичных учреждений, то есть лиц, находящихся на публичной службе, или на службе у юридических лиц публичного права».

Как следует из этого предложения, понятие публичной службы охватывает весь аппарат государственного управления и включает в себя профессиональную деятельность по исполнению полномочий различных субъектов публичного права: федеральных органов государственной власти Российской Федерации; органов государственной власти субъектов Российской Федерации, органов местного самоуправления и образуемых ими публичных объединений, фондов, учреждений и организаций ${ }^{2}$.

Несмотря на различия в масштабах, содержании и степени значимости деятельности всех указанных лиц, в ней общим является то, что ее предметом всегда выступает осуществление публичной власти, а непосредственным результатом - властные решения (нормотворческие или правоприменительные). Следовательно, наличие у указанных лиц особых полномочий на принятие индивидуальных или нормативных, единоличных или кол-

2 См.: Россинский Б.В., Старилов Ю.Н. Административное право: Учебник. М., 2009. С. 304-305. легиальных актов публичной власти и (или) политико-правового характера представляет собой единый сущностный признак, объединяющий таких лиц ${ }^{3}$.

Кроме того, нельзя забывать, что согласно ст. 3 Конституции РФ единственным источником власти в Российской Федерации, носителем суверенитета является ее многонациональный народ. Народ осуществляет свою власть непосредственно (посредством референдума и выборов) или через органы государственной власти и органы местного самоуправления. Осуществляемая народом власть является единой и, как следствие, объединяющим понятием для государственной и муниципальной власти является «публичная власть» ${ }^{4}$.

Исходя из конституционных положений о народном суверенитете следует рассматривать и сущность государственной и муниципальной службы. С этой точки зрения данные виды службы выступают как механизм, инструмент реализации публичной, а именно, государственной и муниципальной власти. Государственные и муниципальные служащие в ходе реализации своих должностных обязанностей исполняют полномочия государственных органов и органов местного самоуправления, посредством которых народ осуществляет свою власть ${ }^{5}$. Следовательно, деятельность служащих также направлена на реализацию государственной политики, государственной власти, служение государству, обществу, в связи с чем их профессиональную деятельность также следует рассматривать как осуществление публичной власти.

Таким образом, государственную и муниципальную службу, а также деятельность лиц, замещающих государственные и муниципальные должности, объединяет единая конституционно-правовая природа реализация публичной власти, что позволяет рассматривать указанные виды деятельности в рамках единого понятия — «публичная служба».

\footnotetext{
См.: Гусев А.В. Российская государственная гражданская служба: проблемы правового регулирования: Дисс. ... д-ра юрид. наук. Екатеринбург, 2009. С. 57.

4 Термин «публичная власть» широко используется Конституционным Судом РФ. См., напр.: Постановление Конституционного Суда РФ от 24 января 1997 г. № 1-П «По делу о проверке конституционности Закона Удмуртской Республики от 17 апреля 1996 года "О системе органов государственной власти в Удмуртской Республике” // Вестник Конституционного Суда РФ. 1997. № 1.

5 См.: Баранник Т.В. К вопросу о становлении публичной службы Российской Федерации // Юридический мир. 2009. № 1. C. 72.
} 
К сожалению, в действующем российском законодательстве не употребляется понятие публичной службы. Однако его официальное нормативное закрепление позволит обеспечить единое направление развития ее составляющих (государственной и муниципальной службы), что, в свою очередь, будет способствовать стабильному функционированию государства в целом. Отсутствие подобной единой политики в вопросе регулирования государственной и муниципальной службы, а также деятельности лиц, замещающих государственные и муниципальные должности, на практике уже привело к ряду проблем.

Например, в ходе реформирования государственной службы были внесены изменения также в законодательство о муниципальной службе, что в определенной степени способствовало сближению указанных видов деятельности. Федеральный закон «О государственной гражданской службе Российской Федерации» определил способы обеспечения взаимосвязи гражданской и муниципальной службы (ст. 7). Ими выступают: а) установление единства квалификационных требований к должностям, б) установление ограничений и обязательств при прохождении службы, в) соотносительность пенсионного обеспечения и прочее. Однако представляется, что по отдельным параметрам эта взаимосвязь носит механический характер. Сущностные черты указанных видов службы остались различными. Федеральный закон «0 муниципальной службе в Российской Федерации», с одной стороны, закрепил понятия, используемые в законодательстве о государственной гражданской службе, - «наниматель», «представитель нанимателя», понятия, подчеркивающие публичный характер деятельности. С другой же стороны, в ст. 2 Закона закреплены понятия «работодатель», «трудовой договор (контракт)», т.е. характерные для трудового права. Исходя из этого, муниципальная служба регулируется как бы между двумя разными отраслями права - публично-правовыми и частноправовыми. Как представляется, рассмотрение государственной и муниципальной службы как видов публичной службы, т.е. в едином ключе позволило бы избежать такой ситуации ${ }^{6}$.

Законодательное закрепление понятия «публичная служба» способствовало бы также возможности решить вопрос об установлении статуса лиц, замещающих государственные должности

6 См.: Там же. субъектов Российской Федерации. В настоящее время единые общие требования к статусу лиц, замещающих государственные должности субъектов Российской Федерации, законодательно не закреплены ${ }^{7}$. Вместе с тем не вызывает сомнения необходимость установления ограничений прав и свобод лиц, замещающих государственные должности. Указанные должностные лица фактически реализуют государственную власть при осуществлении своих полномочий. Соответственно их деятельность должна быть объективной, свободной от влияния третьих лиц, что вынуждает субъекты Российской Федерации самостоятельно определять статус лиц, замещающих государственные должности субъектов Российской Федерации, в том числе устанавливать и ограничения, связанные с замещением государственной должности ${ }^{8}$.

Как уже указывалось, в отличие от отечественного законодательства единое понимание публичной службы принято в некоторых зарубежных государствах. Например, термин французского административного права, который как правило переводят как «государственная служба» на самом деле должен переводиться именно как публичная служба, поскольку под ним понимается «служба в государственных учреждениях и муниципалитетах, а также образуемых ими организациях». Под публичностью службы в данном случае признается ее направленность на достижение общественного или публичного блага.

Широко используется понятие «публичное должностное лицо» и в международных документах (например, в Конвенции ООН против коррупции, против транснациональной организованной преступности, Конвенции Совета Европы об уголовной ответственности за коррупцию, Международном Кодексе поведения государственных должностных лиц). Этим понятием обозначается любое избранное или назначенное лицо, замещающее должность (независимо от ее уровня) в законодательном, исполнительном, административном или

\footnotetext{
За исключением высшего должностного лица субъекта Российской Федерации, депутатов законодательного (представительного) органа государственной власти, судей конституционного (уставного) суда. См.: Федеральный конституционный закон «О судебной системе Российской Федерации», Федеральный закон «Об общих принципах организации законодательных (представительных) и исполнительных органов государственной власти субъектов Российской Федерации».

8 См.: Баранник Т.В. Указ. соч. С. 73.
} 
судебном органе на постоянно или на временной основе, за плату или без оплаты труда9.

Однако, несмотря на активное использование понятия публичной службы в зарубежном законодательстве и международном праве, в отечественной юридической литературе полноценная характеристика этого понятия отсутствует. Представляется, что положение должностного лица в системе государственной и муниципальной службы нужно изучать исключительно с позиций системности, основным признаком которой выступает целостность.

По объективным признакам аппарат управления является системным объектом. При этом в нем выделяются метасистема - государство, а также многочисленные подсистемы, среди которых находится также публичная служба. В качестве подсистем аппарата публичной службы действуют отдельные органы, которые подразделяются на структурные подразделения и должностных лиц. При этом если структурные подразделения также выступают системами и могут быть подвергнуты последующему делению, то должностные лица, также как и должности, являются неделимыми элементами системы, то есть минимальными ее компонентами.

В то же время трудно согласиться с А.Н. Аверьяновым, который указывает на относительную неделимость элементов, поскольку каждый из них сам по себе выступает системой, и так же состоит из элементов. Верным является замечание Б.П. Курашвили о том, что должностное лицо выступает простейшей (первичной) структурной единицей аппарата управления. При этом нужно учитывать, что должностным лицом признается в данном случае не конкретный человек, обладающий правами и обязанностями, а понятие, которое сходно с понятием должности, являющееся простейшим носителем правосубъектности. Другое дело, что элементы системы, в том числе и должностное лицо, можно исследовать с системных позиций.

В теории организаций системой признается совокупность элементов и связей между ними, обладающих признаком целостности, т.е. возникновением на уровне системы в результате взаимодействия ее частей свойств, не присущих отдельным элементам, равно как и их простой сумме. Исходя из этого, аппарат государственного управления можно представить в виде целостного формирования, части которого связаны между собой, опреде-

\footnotetext{
9 См.: Гусев А.В. Указ. соч. С. 54.
}

ленным образом упорядочены в своих отношениях и постоянно взаимодействуют друг с другом.

Одной из систем управления государством является система публичной службы. Следовательно, понятия «публичная служба» и «аппарат государственного управления» должны соотноситься друг к другу как частное к общему. Система публичной службы в свою очередь является общим для входящих в нее систем и элементов управления. Должностное лицо является одним из важнейших из этих элементов.

Таким образом, публичная служба понимается нами как единая система, объединяющая всех служащих, осуществляющих свою деятельность в сфере государственного управления. Этот термин имеет право на существование в юридической науке, поскольку позволяет объединить в едином правовом пространстве служащих, характеризующихся схожим правовым статусом.

Вместе с тем нельзя не обратить внимание, что понятие публичной службы является весьма неоднородным. В ее систему входят государственно-служебные отношения, регулируемые публичным правом, и частноправовые отношения, регулируемые отраслями частного права. Так, правовое регулирование служебных отношений должностного лица органа местного самоуправления осуществляется административным и муниципальным законодательством, а служебные отношения должностного лица, которое занимает должность, например в фонде, образованном местным органом власти, регулируются трудовым законодательством.

Учитывая это, с нашей точки зрения, публичную службу можно рассматривать в узком и в широком смыслах.

Публичной службой в широком смысле признается профессиональная деятельность по исполнению полномочий федеральных органов государственной власти РФ, органов государственной власти субъектов РФ, органов местного самоуправления, а также образуемых ими публичных организаций ${ }^{10}$.

Публичной службой в узком смысле признается профессиональная деятельность по исполнению полномочий лишь федеральных органов государственной власти РФ, органов государственной власти субъектов РФ и органов местного самоуправления.

10 См.: Дмитриев Ю.А., Полянский И.А., Трофимов Е.В. Административное право. М., 2009. - С. 217. 
Представляется, что узкое понимание публичной службы наиболее верное. Следует согласиться с подходом А.В. Гусева в том, что понимание публичной службы в широком смысле приводит к тому, что она «становится весьма аморфным, неопределенным явлением» ${ }^{11}$.

Небезуспешная, на наш взгляд, попытка определения понятия публичной службы предпринята Т.В. Баранником, который формулирует понятие публичной службы на основе определений понятий «государственная служба», «муниципальная служба», «деятельность лиц, замещающих государственные и муниципальные должности». Публичной службой им признается профессиональная деятельность граждан Российской Федерации, а в случаях, предусмотренных законодательством, и иностранных граждан, замещающих должности государственной службы, муниципальной службы, а также государственные должности по исполнению полномочий государственных органов, органов местного самоуправления, полномочий Российской Федерации и субъектов Российской Федерации, обеспечению исполнения полномочий лицами, замещающими государственные должности ${ }^{12}$.

А.В. Гусев при характеристике понятия публичной службы предлагает исходить не только из функционального критерия, то есть ее направленности на реализацию общественно или государственно значимых функций, но и использовать иные, более четкие критерии: наличие определенных функций по участию в управлении делами публичной власти; принадлежность к ее определенной организационно-правовой форме; наделение лица публичной службы специальным статусом, наличие особых правил допуска к службе, запретов и ограничений, условий труда и социальной защиты, особых условий и порядка прохождения и прекращения службы ${ }^{13}$.

Согласно ч. 4 ст. 32 Конституции РФ право граждан закреплено только на доступ к государственной службе. Это связано прежде всего с тем, что в 1993 г., когда принималась Конституция РФ, понятие государственной службы трактовалось значительно шире, чем в настоящее время, совпадая во многом по содержанию со понятием публичной службы.

\footnotetext{
11 Гусев А.В. Указ. соч. С. 52.

12 См.: Баранник Т.В. Указ. соч. С. 73.

13 См.: Гусев А.В. Указ. соч. С. 54.
}

Однако мы выступает против закрепления права граждан РФ на службу вообще, как, например, это предлагает В.М. Манохин. По нашему мнению, данная норма направлена лишь на конституционное закрепление одного из способов осуществления гражданами РФ права на участие в управлении государством. Признание права граждан на службу в коммерческих и негосударственных организациях не способствует реализации указанному назначению. Право на службу в таких учреждениях уже закреплено в ст. 37 Конституции РФ.

Представляется, что публичная служба должна основываться на тех же принципах, что и государственная и муниципальная служба. Эти принципы сформулированы в Федеральных законах «0 системе государственной службы Российской Федерации» и «О муниципальной службе в Российской Федерации». К ним прежде всего относятся принципы верховенства Конституции РФ и федеральных законов, приоритета прав и свобод человека и гражданина, равного доступа граждан к государственной службе, внепартийности государственной службы и пр.

Однако помимо указанных принципов правовое регулирование публичной службы должно основываться, на наш взгляд, также на следующих дополнительных принципах: а) независимости составляющих системы публичной службы в Российской Федерации; б) принципиального равенства всех публичных служащих, независимо от рода их службы; в) равного доступа граждан к публичной службе.

Учитывая изложенное, в настоящее время актуальной становится проблема унификации законодательства в рассматриваемой сфере. При этом наметилось несколько различных подходов к ее решению. Одни авторы, признавая необходимость усиления общности правового регулирования государственной гражданской и муниципальной службы, полагают достаточным закрепить единство их целей, функций, принципов и некоторых общих подходов к правовому регулированию их организации ${ }^{14}$. Другие ученые, основываясь на тезисе о полной «статусно-функциональной идентичности» указанных видов публичной службы, настаивают на их полной интеграции путем поглощения муниципальной службы гражданской, воссоздании общего законодательства о

\footnotetext{
14 См., напр.: Иванов В.П. Реформирование государственной службы: вопросы и перспективы // Журнал российского права. 2003. № 5.
} 
государственной гражданской и муниципальной службы ${ }^{15}$. Третья группа ученых высказывается о необходимости объединения гражданской и муниципальной службы и деятельности, о принятии единого базового закона (либо даже кодекса) публичной службы ${ }^{16}$.

Придерживаясь последней из указанных позиций, Т.В. Баранник, например, предлагает принять федеральный закон «0 публичной службе Российской Федерации», представляющий собой основу для всех видов государственной и муниципальной службы, а также деятельности лиц, замещающих государственные и муниципальные должности. В качестве ключевых положений закона указанный автор предлагает выделить:

- понятие и состав публичной службы;

- основы правового статуса государственных и муниципальных служащих, лиц, замещающих государственные должности (их права, обязанности, ограничения, связанные с занимаемыми ими должностями);

- основные гарантии деятельности указанных лиц;

- обеспечение взаимосвязи всех видов государственной службы, муниципальной службы и деятельности лиц, замещающих государственные должности ${ }^{17}$.

Мы также склоняемся к третьей группе авторов и полагаем целесообразным принятие Федерального закона «Об основах публичной службы в Российской Федерации», где помимо указанных выше принципов публичной службы могли бы найти отражение вопросы, не рассмотренные в законах «О системе государственной службы Российской Федерации» и «О муниципальной службе в Российской Федерации». В круг таких вопросов могут входить: понятие должностного лица публичной службы, их классификация, права и обязанности должностных лиц, установление общих ограничений и запретов и т.д.

Таким образом, с учетом проведенного в настоящем параграфе исследования, можно сделать следующие выводы:

1. В настоящее время целесообразно формирование в теории и в законодательстве понятия «публичная служба», что позволит обеспечить единое направление развития государственной и муниципальной службы, позволит устранить имеющиеся на практике правотворческие и правоприменительные проблемы.

2. Наиболее предпочтительным представляется понимание публичной службы в узком смысле, т.е. как профессиональной деятельности по исполнению полномочий федеральных органов государственной власти РФ, органов государственной власти субъектов РФ и органов местного самоуправления.

3. В целях унификации законодательства о публичной службе предлагается принять федеральный закон «Об основах публичной службы Российской Федерации», который бы отразил в своем содержании общие права, обязанности, гарантии, правоограничения и другие элементы правового статуса должностных лиц публичной службы.

\section{Библиография:}

1. Буравлев Ю.М. Конституционно-правовые основы государственной службы и целесообразность ее интеграции с муниципальной службой // Конституционное и муниципальное право. 2006. № 10.

2. Баранник Т.В. К вопросу о становлении публичной службы Российской Федерации // Юридический мир. 2009. № 1.

3. Гусев А.В. Российская государственная гражданская служба: проблемы правового регулирования: Дисс. ... д-ра юрид. наук. Екатеринбург, 2009. С. 57.

\footnotetext{
15 См., напр.: Буравлев Ю.М. Конституционно-правовые основы государственной службы и целесообразность ее интеграции с муниципальной службой // Конституционное и муниципальное право. 2006. № 10. С. 34 .

16 См., напр.: Казанцев Н.М. К вопросу о совершенствовании антикоррупционной государственной политики // Аналитический вестник Совета Федерации Федерального Собрания Российской Федерации. М., 2008. С. 6.

17 См. Баранник Т.В. Указ. соч. С. 74.
} 
4. Дмитриев Ю.А., Полянский И.А., Трофимов Е.В. Административное право. М., 2009.

5. Иванов В.П. Реформирование государственной службы: вопросы и перспективы // Журнал российского права. 2003. № 5.

6. Казанцев Н.М. К вопросу о совершенствовании антикоррупционной государственной политики // Аналитический вестник Совета Федерации Федерального Собрания Российской Федерации. М., 2008.

7. Россинский Б.В., Старилов Ю.Н. Административное право. М., 2009.

8. Комахин Б.Н. К вопросу об определении критериев эффективности административно-правового регулирования публично-служебных отношений в контексте модернизации государственного управления и инновационного развития // Полицейская деятельность. - 2013. - 4. - С. 289-295. DOI: $10.7256 / 2222-1964.2013 .4 .9452$.

9. М.В. Костенников, А.В. Куракин, И.Н. Кошелев Административно-правовое регулирование обеспечения собственной безопасности и противодействия коррупции в органах внутренних дел (ч. 1). // Административное и муниципальное право. - 2011. - 1. - С. 40-47.

10. Костенников М.В., Куракин А.В., Кулешов Г.Н., Несмелов П.В. Административно-правовое регулирование информационного обеспечения государственной гражданской службы в контексте противодействия коррупции (ч. 2) // Административное и муниципальное право. - 2012. - 11. - С. 14-33.

\section{References:}

1. Buravlev Yu.M. Konstitutsionno-pravovye osnovy gosudarstvennoi sluzhby i tselesoobraznost' ee integratsii s munitsipal'noi sluzhboi // Konstitutsionnoe i munitsipal'noe pravo. 2006. № 10.

2. Barannik T.V. K voprosu o stanovlenii publichnoi sluzhby Rossiiskoi Federatsii // Yuridicheskii mir. 2009. № 1.

3. Gusev A.V. Rossiiskaya gosudarstvennaya grazhdanskaya sluzhba: problemy pravovogo regulirovaniya: Diss. ... d-ra yurid. nauk. Ekaterinburg, 2009. S. 57.

4. $\quad$ Dmitriev Yu.A., Polyanskii I.A., Trofimov E.V. Administrativnoe pravo. M., 2009.

5. Ivanov V.P. Reformirovanie gosudarstvennoi sluzhby: voprosy i perspektivy // Zhurnal rossiiskogo prava. 2003. № 5.

6. Kazantsev N.M. K voprosu o sovershenstvovanii antikorruptsionnoi gosudarstvennoi politiki // Analiticheskii vestnik Soveta Federatsii Federal'nogo Sobraniya Rossiiskoi Federatsii. M., 2008.

7. Rossinskii B.V., Starilov Yu.N. Administrativnoe pravo. M., 2009.

8. Komakhin B.N. K voprosu ob opredelenii kriteriev effektivnosti administrativno-pravovogo regulirovaniya publichno-sluzhebnykh otnoshenii $\mathrm{v}$ kontekste modernizatsii gosudarstvennogo upravleniya i innovatsionnogo razvitiya // Politseiskaya deyatel'nost'. - 2013. - 4. - C. 289-295. DOI: 10.7256/22221964.2013.4.9452.

9. M.V. Kostennikov, A.V. Kurakin, I.N. Koshelev Administrativno-pravovoe regulirovanie obespecheniya sobstvennoi bezopasnosti i protivodeistviya korruptsii v organakh vnutrennikh del (ch. 1). // Administrativnoe i munitsipal'noe pravo. - 2011. - 1. - C. 40-47.

10. Kostennikov M.V., Kurakin A.V., Kuleshov G.N., Nesmelov P.V. Administrativno-pravovoe regulirovanie informatsionnogo obespecheniya gosudarstvennoi grazhdanskoi sluzhby v kontekste protivodeistviya korruptsii (ch. 2) // Administrativnoe i munitsipal'noe pravo. - 2012. - 11. - C. 14-33. 